\title{
CHALLENGES FOR PRIMARY HEALTHCARE PROFESSIONALS IN CARING FOR WOMEN WITH POSTPARTUM DEPRESSION
}

\author{
Bianca de Macêdo Meiraํㅗ Pauliany Alencar de Souza Pereira², Maria de Fátima Araújo Silveiraª , Dulce \\ Maria Rosa Gualda ${ }^{4}$ Hudson Pires Oliveira Santos Jr $r^{5}$
}

\begin{abstract}
${ }^{1}$ Specialist in Woman's Health. Nurse at Hospital Dom Malan. Petrolina, Pernambuco, Brazil. E-mail: bianca_meira_bi@hotmail.com
${ }^{2}$ Specialist in Woman's Health. Nurse at Hospital Dom Malan. Petrolina, Pernambuco, Brazil. E-mail: paulianyany@hotmail.com

${ }^{3}$ Ph.D. in Nursing. Professor, Departamento de Enfermagem, Universidade Estadual da Paraíba. Campina Grande, Paraíba, Brazil. E-mail: fatimasilveir@uol.com.br

${ }^{4}$ Ph.D. in Nursing. Professor, Escola de Enfermagem, Universidade de São Paulo. São Paulo, São Paulo, Brazil. E-mail: drgualda@usp.br ${ }^{5}$ Ph.D. in Science. Post-doctoral fellow, School of Nursing, Duke University. Durham, North Carolina, USA. E-mail: hudson. santos@duke.edu
\end{abstract}

\begin{abstract}
The aim of this study was to explore the challenges for primary healthcare professionals in caring for women with postpartum depression, in order to learn which tools are used for the identification of these women, as well as ways of working to restore their health. This qualitative descriptive study was conducted in healthcare units in Campina Grande, Paraíba. Data were collected by field observation and a semi-structured interview, which was administered to 16 healthcare professionals. The results describe healthcare professionals' difficulties in identifying and treating women with postpartum depression, because of the limited focus on physiological developmental aspects of gestation and postpartum. The professionals reported limited knowledge on how to assess emotional changes related to the postpartum period. Primary healthcare professionals need to be educated to identify and treat women with postpartum depression, and practice guidelines and protocols must be established to guide evidence-based practice. DESCRIPTORS: Depression, postpartum. Postpartum period. Women's health. Maternal-child nursing. Primary care nursing.
\end{abstract}

\section{DESAFIOS PARA PROFISSIONAIS DA ATENÇÃO PRIMÁRIA NO CUIDADO À MULHER COM DEPRESSÃO PÓS-PARTO}

RESUMO: O objetivo deste estudo foi conhecer os desafios dos profissionais da atenção primária no cuidado às mulheres com depressão pós-parto, buscando identificar quais as ferramentas utilizadas para a detecção dessas mulheres, bem como as formas de atuação para o restabelecimento da sua saúde. Trata-se de um estudo qualitativo-descritivo, realizado em unidades de saúde no município de Campina Grande, Paraíba. A coleta de dados ocorreu por observação e entrevista semiestruturada aplicada a 16 profissionais de saúde. Os resultados descrevem a dificuldade de profissionais para identificar e tratar a depressão pós-parto, pois o foco da assistência é limitado aos aspectos fisiológicos do desenvolvimento da gestação e do pós-parto. Os participantes relatam limitado conhecimento para avaliar alterações emocionais relacionadas a esse período. Os profissionais da atenção primária em saúde precisam ser capacitados para identificar e tratar mulheres com depressão pós-parto, bem como manuais e protocolos assistenciais precisam ser estabelecidos para guiar a prática baseada em evidências científicas.

DESCRITORES: Depressão pós-parto. Período pós-parto. Saúde da mulher. Enfermagem materno-infantil. Enfermagem de atenção primária.

\section{DESAFÍOS PARA LOS PROFESIONALES DE ATENCIÓN PRIMARIA EN EL CUIDADO DE MUJERES CON DEPRESIÓN POSPARTO}

RESUMEN: El objetivo de este estudio fue comprender los desafíos para los profesionales de la atención primaria en el cuidado de las mujeres con depresión posparto, con el fin de identificar cuales herramientas se utilizan para la detección de estas mujeres, así como los procedimientos utilizados para reestablecer su salud. Es un estudio cualitativo descriptivo realizado en las unidades de salud del municipio de Campina Grande, estado de Paraíba. Los datos fueron reunidos mediante la observación y la realización de entrevistas semiestructuradas con 16 profesionales de salud. Los resultados describen la dificultad que enfrentan los profesionales para identificar y tratar la depresión posparto, debido al enfoque limitado de la asistencia a los aspectos fisiológicos del desarrollo de la gestación y posparto. Los profesionales describen un conocimiento limitado para evaluar las alteraciones emocionales relacionadas a este periodo. Los profesionales de atención primaria en salud deben ser capacitados para identificar y tratar a las mujeres con depresión posparto. Los manuales y protocolos de asistencia deben ser establecidos para guiar la práctica basada en la evidencia científica.

DESCRIPTORES: Depresión posparto. Periodo posparto. Salud de la mujer. Enfermería maternoinfantil. Enfermería de atención primaria. 


\section{INTRODUCTION}

Postpartum depression (PPD) is a frequent health problem for women in the postpartum period. It can begin within the first four weeks postpartum or up to one year after birth. It is considered a serious public health problem because of its high prevalence, ranging from $10-20 \%$ depending on the region and screening instruments used..$^{1-2}$

This disorder features a multifactorial etiology, with risk factors including: socioeconomic conditions, difficult marital relationship, unwanted pregnancy, low education level, low maternal age, pregnancy associated with stressors, among others. ${ }^{1,-4}$ Clinical PPD manifestations can include: persistent dismay, feelings of guilt, sleep disturbances, suicidal ideas, fear or recurrent thoughts of hurting the child, decreased appetite and libido, decreased mental functioning level, and obsessive or overvalued ideas. ${ }^{5}$

The diagnosis is complex, because there are no exclusive physiological parameters. Therefore, instruments have been created to measure and characterize PPD symptoms. Among these instruments, the Edinburgh Postnatal Depression Scale (EPDS) is the most commonly used. It has been translated to Portuguese and validated in Brazil, but it has not yet been incorporated into routine primary health care public services. ${ }^{6-8}$

The EPDS is a self-report scale that measures the presence of depressive symptoms in the postnatal period. It is a suitable and affordable tool for professionals to screen for postpartum depressive symptoms. Once the symptoms are screened, health care professionals have the opportunity to establish interventions and early treatment, thereby minimizing the negative effect PPD can cause in the mother-infant relationship and in the child's development, and restoring the family and social life of the woman. ${ }^{9}$ When postpartum mood disorders are left untreated there may be severe complications, among which the most severe include infanticide and suicide. ${ }^{10}$

In the Brazilian context, professionals in the primary health care system known as the Family Health Strategy (FHS) are in a favorable position to contribute to women's coping with the disease, since they provide care for most women from pregnancy through the postpartum period, more easily identifying factors or conditions related to the risks and harms to the health of the women and their newborn, especially PPD. ${ }^{7-8,11-12}$

Given the above, this study was performed to identify the challenges for FHS professionals in caring for women with PPD, particularly seeking to learn which tools are used for the identification of women with PPD, and the ways they act to restore their health.

\section{METHODS}

This was a qualitative, descriptive study ${ }^{13}$ performed in the FHS health care units of Campina Grande, Paraíba, Brazil. Currently, $87 \%$ of this city has coverage by the FHS. The sample consisted of nurses and physicians, with the following inclusion and exclusion criteria: 1 ) inclusion criteria: being part of the basic family health team and providing direct care to women in the pregnant-puerperal cycle; 2) exclusion criteria: being a medium/technical level professional or having less than six months experience in family health teams. The participants were 16 professionals (12 nurses and four female physicians), identified in this article by the letters " $\mathrm{N}$ ", for nurses, and " $\mathrm{P}$ " for physician, and followed by an ordinal number to identify the order of the interviews.

Data were collected by means of semistructured interviews, observation and daily recordings in a field diary. The interviews lasted a mean of 25 minutes and were performed with open-ended questions on professional knowledge and experience with PPD. Data were collected from December of 2011 to May of 2012, and the collection was interrupted when the researchers identified data saturation. ${ }^{14}$

For data analysis, thematic inductive analysis was used..$^{15-16}$ Interviews were transcribed by two researchers who collected the data. Next, these researchers read the interviews to familiarize themselves with the content. In the next step, the researchers coded the interviews line by line to identify the health care professionals' perception about the care of women with PPD, and the strategies used for the care of these women. The identified codes were then grouped, according to similarities, into thematic categories. To complete the analysis, the two researchers compared the thematic categories and discussed agreement regarding the content of the interviews. Other 
researchers critically assessed the description and the final content of the thematic categories regarding the interviews to ensure the validity of the identified themes. ${ }^{16}$

As for the ethical criteria, the research project was approved by the Research Ethics Committee of the Paraíba State University and the City Health Secretariat (Protocol 0123.0.133.000-09).

\section{RESULTS}

Data analysis allowed for identification of the following thematic categories: 1) Difficulty of health care professionals in identifying women with PPD; 2) Lack of care towards PPD prevention during the prenatal period; and 3) Lack of strategies for caring for women with PPD.

\section{Difficulty of health care professionals in identifying women with postpartum depression}

Although the professionals recognized certain risk factors and PPD symptoms in the women, there was no systematic knowledge to identify this disorder. One of the nurses reported her experience with a postpartum woman with signs that she considered to be clues of PPD:

the mother reported that she had left the maternity service crying a lot and rejecting the baby. She didn't want to breastfeed, didn't interact at all with the child. She was a little aggressive as well. There were aggressive peaks and sensitivity peaks, crying a lot. Then I figured it could be postpartum depression (N1).

Even when confronted with signs that evidence depressive symptoms, professionals refer to this as "predisposition" to DPP.

What we had here in this unit were people who we considered predisposed to PPD. One of them reported rejection of the fetus and a desire to kill herself (N11).

On the other hand, we noted that the professionals demonstrated insecurity by stating that it really was PPD when they handled women who had mild symptoms.

There were, like, mild symptoms, which I don't know if they could be considered depression. They came on one day but on the other day she was okay. It was more like... I don't know if it can be considered depression, I really don't know ... it was like, a symptom of much concern towards that new person ... I believe it was perhaps an adaptation (N2).
This lack of perception about PPD is further reinforced when the professionals referred to community health workers or family members of women as people who noticed the signs of PPD and brought this information to the health care unit:

we identify it in the patient's family complaint or in the reports brought by the heal th care agent (E7).

[...] it is the health care agent who has very good clinical eye and identifies some situations within the community [...] (N7).

Part of this difficulty identifying PPD cases can be related to the lack of knowledge of the health care professionals about PPD and the available mechanisms for screening. The participants reported lack of knowledge about the specific instruments for screening. They state they did not learn about it while taking classes in their major and did not have experience administering scales.

I don't know anything [PPD screening scales]. When I went to college, no one showed me anything. As I've never worked with depression, I haven't used any scales (N10).

\section{Lack of care towards postpartum depression prevention during the prenatal period}

Although prenatal care enables early identification of women more likely to have PPD, it is observed in the statements that health care professionals describe clinical practice from the protocols defined by the Ministry of Health, which are not extended towards mood disorders in the pregnancy-puerperal cycle.

I do the routine prenatal care established by the Ministry of Health, I request the tests, do the physical examination (M3).

We work with prenatal follow-up according to the Ministry of Health. We have at least seven prenatal appointments, starting with the agents' role, diagnosis of pregnancy and then monthly monitoring, weight check, blood pressure, all that thing (N11).

Most professionals report performing educational activities by means of groups for pregnant women. However, even in terms of these groups, the professionals are still centered on the physiological aspect of pregnancy and, although they state they are addressing emotional aspects, they do not directly address postpartum mood disorders, such as PPD. 
In this unit, we work with a group of pregnant women, we call it pregnancy course. [In] each course, we schedule about ten meetings. Then we talk about bodily changes, breastfeeding, vaccinations, care of the newborn, follow-up, and we also talk about this psychological part (N11).

\section{Lack of strategies for caring for women with postpartum depression}

This category is evidenced by statements revealing the approaches adopted by the health care professionals in the postpartum period towards women with PPD. In this sense, the interviewees did not describe any care strategy provided in the health care unit, or even in the community, beyond the standard for the postpartum care. A home visit is one of them. However, they do not approach the possible psychological problems of the woman.

[...] after childbirth, we do a visit ... then we have a conversation and they report how delivery was [...] (N7).

I usually do home visiting [...] (N5).

When they find themselves facing a possible PPD, some professionals report that the only care they provide is listening to the mothers, regardless of the severity of the reported situation: (N11).

[...] we really only listen to what she has to say

we give support, we give our listening (N12).

Moreover, the professionals assumed they were unprepared to handle mothers affected by PPD. Among the listed reasons were the lack of training and lack of experienced personnel to care for women with PPD:

it's difficult for us to provide care for these women because I have neither training nor experience to intervene (N10).

The participants described referring these women to the Family Health Care Center (FHCC) or the Center for Psychosocial Care (CPC), specialized services in psychiatric care. The participants state that they do not know a specific service directed to this demographic and refer to the psychiatric services that are references for serious mental disorders:

[...] we are no psychiatrists, we're general practitioners, so we usually do the referral (P2).

which specialized service do we have? I don't know! There may even be one, but I don't know. So I refer to CPC (N5).

\section{DISCUSSION}

The results of the study show that the FHS professionals witness care situations in which women potentially have PPD. From this experience, the study participants listed possible risk factors and some of the symptoms, but they still found it difficult to identify PPD, prevent it or intervene early, because they are unaware of the screening methods and have limited interventions when the disorder is recognized.

With regard to the risk factors associated with PPD, the participants report isolated factors. The literature suggests that the risk factors for PPD are a set of biological, obstetrical, psychological and social factors that are interrelated and contribute to precipitation or worsening of maternal depression. ${ }^{17}$ Regarding symptoms, only some signs of psychological distress, such as sadness, anxiety and fear, have been described. However, PPD is characterized by a broad spectrum of symptoms; at least five of these symptoms must be present for a possible diagnosis. ${ }^{18}$

In most of the participants' statements there is a predominant rejection of the baby. However, rejection and infanticide cannot be considered the main determinants of PPD cases. Some women may experience an obsessive behavior towards the child, in which mothers spend most of the time looking after the babies and do not let other family members participate in this process. ${ }^{19}$ The PPD can favor the occurrence of both abuse and neglect, especially when the depressive symptoms are persistent and intense. ${ }^{9}$ Findings such as infanticide and suicide are among the most serious complications of puerperal disorders, without appropriate intervention.

Signs of exhaustion and depression are commonly considered normal in motherhood by health care professionals, which enable iatrogenic complications in their practices. Other studies on mental disorders during pregnancy and the postpartum period also show that depressive symptoms are not commonly diagnosed or perceived by primary health care professionals. ${ }^{7,19-20}$ Identifying women with risk factors by monitoring during prenatal care is essential. It is worth highlighting the importance of nurses identifying the multiple risk factors and symptoms related to PPD and the care strategies for screening of depressive symptoms. Early detection strategies can reveal the existence of signs and symptoms of psychological 
distress that can be investigated during the course of pregnancy. ${ }^{4,8,20}$

Prenatal care for pregnant women by a multidisciplinary team, combining efforts and knowledge from different professionals, is an excellent opportunity to prevent, detect and treat affective disorders and hence minimize the negative effects of PPD in the mother-child relationship. ${ }^{21} \mathrm{How}-$ ever, with regard to prenatal care behaviors to prevent PPD, this study shows that professionals base their care on the protocols of the Ministry of Health, in the Technical Prenatal and Puerperal Manual. This document describes the importance of attention to the emotional aspects during pregnancy, childbirth and the postpartum period, but sparingly, despite considering the fact that actions based only on physical aspects are not sufficient. However, the manual does not offer guidelines or care protocols to be implemented in clinical practice, although it highlights the importance of active listening and proposes that individual and group educational activities should be performed. ${ }^{21}$

Groups for pregnant women can be thought of as moments for an early approach to the PPD by means of assessing self-esteem, the social support network, and the mothers' feelings. The willingness to listen to the pregnant woman, using a welcoming approach, is an essential measure for this assessment. Through interaction, the professional can also identify changes in mood, thought and behavior that are suggestive of possible psychiatric disorders. ${ }^{22-23}$ We observed that a few participants in this study adopted this practice, and did not directly address PPD, although they approached emotional aspects. The participants' statements in this study show that it is not common to include information and discussion about the emotional and psychological aspects of pregnancy in group activities.

The participants also exposed that they were unaware of DPP screening instruments, arguing that the knowledge of specific instruments for the screening of this disease and a more accurate assessment are a responsibility of mental health experts. The participants were unaware that there are scales, such as the EPDS, which can be implemented in the public health system, due to their simplicity, rapid implementation and low cost, and can be used by any health care professional. ${ }^{24}$

The statements of health care professionals show that they lack strategies for early detection of women at risk for PPD, as well for caring for women with symptoms of the disease in the service, thereby resulting in the referral to other health care services. The participants then described referring these women to psychiatric services. Therefore, their behavior followed the referral logic, without involvement and monitoring of women with this type of suffering in the FHS units. ${ }^{20}$

Some participants stated that they listened to and supported women, but only when the depressive signs were identified by community health agents and the women's family. However, this is a non-systematic listening: professionals state that they have no knowledge of possible ways of acting. The management of PPD includes psychoeducational programs, psychotherapy and medications, which have yet to be extensively studied and adapted to the Brazilian context.

The lack of knowledge about the patient's mental health results in limited care for women and their families during the postpartum period. In this sense, the inclusion of curricular components related to mental health in the postpartum period could serve as a qualification instrument for nurses and physicians to handle women with PPD. Thus, the strategies described above as care for prenatal, pregnant and postpartum women could be used more consciously to strengthen the support network for the women. This qualification would facilitate communication between the FHS professionals in the dialogue that is required with other levels of care, especially when there is need to refer and counter-refer women in the health care system.

\section{CONCLUSION}

Although the study participants were in primary health care and had the opportunity to observe women since the beginning of their pregnancy, the care focus of prenatal care is reported by them as being limited to the physiological aspects of pregnancy and postpartum development. This lack of integrated actions and interventions causes delays in the detection of women with depression and improper referrals to reference services that can lead to worsening of the clinical condition of the pregnant and postpartum women, thereby harming the woman, the child, the family and their surroundings.

The reality shows the complexity of the problem, either because of the gap existing with 
the Ministry of Health, which does not elaborate care protocols for this disease in primary care, or because of the deficient training of health care professionals, in addition to the care model, which does not prioritize the phenomena in the psychosocial dimension.

Studies are needed to determine ways to educate the FHS professionals and to establish practical protocols so that professionals in the Brazilian health system can identify and treat women with PPD at the level of primary care, thereby enabling actions to ensure the promotion of their health, and mitigating potential consequences in family relationships and the development of their children.

\section{REFERENCES}

1. Wisner KL, Sit DK, McShea MC, Rizzo DM, Zoretich RA, Hughes CL, et al. Onset timing, thoughts of self-harm, and diagnoses in postpartum women with screen-positive depression findings. JAMA Psychiatry. 2013; 70(5):490-8.

2. Halbreich U, Karkun S. Cross-cultural and social diversity of prevalence of postpartum depression and depressive symptoms. J Affect Disord. 2006; 91(2-3):97-111.

3. Cantilino A, Zambaldi CF, Albuquerque T, Paes JA, Montenegro AC, Sougey EB. Postpartum depression in Recife - Brazil: prevalence and association with bio-socio-demographic factors. J Bras Psiquiatr. 2010; 59(1):1-9.

4. Santos Junior HPO, Silveira MFA, Gualda DMR. Postpartum depression: a latent problem. Rev Gaúcha Enferm. 2009; 30(3):516-24.

5. Beck CT. State of the science on postpartum depression: what nurse researchers have contributed-part 2. MCN Am J Matern Child Nurs. 2008; 33(3):151-6.

6. Santos IS, Matijasevich A, Tavares BF, Barros AJ, Botelho IP, Lapolli C, et al. Validation of the Edinburgh Postnatal Depression Scale (EPDS) in a sample of mothers from the 2004 Pelotas Birth Cohort Study. Cad Saude Publica. 2007; 23:2577-88.

7. Santos Junior HPO, Gualda DMR, Silveira MFA, Hall WA. Postpartum depression: the (in) experience of Brazilian primary healthcare professionals. J Adv Nurs. 2013; 69(6):1248-58.

8. Valença CN, Germano RM. Preventing the postpartum depression in family health strategy: nurses' actions in the prenatal. Rev Rene. 2010; 11(2):129-39.

9. Field T. Postpartum depression effects on early interactions, parenting, and safety practices: a review. Infant Behav Dev. 2010; 33(1):1-6.
10. Barr J, Beck CT. Infanticide secrets: qualitative study on postpartum depression. Can Fam Physician. 2008; 54:1716-93.

11. Hegadoren K, Norris C, Lasiuk G, Silva DGV, Chivers-Wilson $\mathrm{K}$. The many faces of depression in primary care. Texto Contexto Enferm. 2009; 18(1):155-64.

12. Kawata, LS MishimaSM, Chirelli MQ, Pereira MJB, Matumoto S, Fortuna CM. The performances of the nurse in family health: building competence for care. Texto Contexto Enferm [online]. 2013 [cited 2014 Jul 14]; 22(4): 961-70. Available from: http:/ / www.scielo.br/ scielo.php?pid=S010407072013000400012\&script=sci_arttext\&tlng=en

13. Sandelowski M. What's in a name? Qualitative description revisited. Res Nurs Health. 2010; 33:7784.

14. Sandelowski M. Sample size in qualitative research. Res Nurs Health. 1995; 18(2):179-83.

15. Braun V, Clarke V. Using thematic analysis in psychology. Qual Res Psychol. 2006; 3(2):77-101.

16. Miles BM, Huberman AM, Saldaña J. Qualitative data analysis: a methods sourcebook. Thousand Oaks (US): SAGE Publications; 2014.

17. Gomes LA, Torquato VS, Feitosa AR, Souza AR, Silva MA, Pontes RJS. Identifying the risk factors for postpartum depression: importance of early diagnosis. Rev Rene. 2010; 11(1):117-23.

18. American Psychiatric Association (APA). Diagnostic and statistical manual of mental disorders.5th ed. Arlington (US): American Psychiatric Publishing; 2013.

19. Santos Jr HPO, Sandelowski M, Gualda DMR. Bad thoughts: early mothering by Brazilian women experiencing postpartum depression. Midwifery. 2014; 30(6):788-94.

20. Alves EP, Silva PMC, Azevedo, EB, Filha MOF. The knowledge of family health nurses' about psychological disorders along the postpartum time. Rev Eletr Enfern [Internet]. 2011 [cited 2014 Feb 16]; 13(3):529-36. Available from: http:/ / www.fen.ufg. br/revista/v13/n3/v13n3a19.htm

21. Ministério da Saúde (BR). Prenatal and postpartum: qualified and humanized assistance [Internet]. Brasília (DF): Ministério da Saúde; 2006 [cited 2014 Feb 16]. Available from: http://bvsms.saude. gov.br/bvs/publicacoes/manual_pre_natal_ puerperio_3ed.pdf

22. Silva FCS, Araújo TM, Araújo MFM, Carvalho CML Caetano JA. Postpartum depression in puerperal women: knowing the interactions among mother, son and family. Acta Paul Enferm. 2010; 23(3): 411-16.

23. Sousa DD, Prado LC, Piccinini CA. Representations concerning motherhood in postpartum depression context. Psicol Refl Crit. 2011; 24(2):335-43. 
24. Autin MP, The Marcé Society Position Statement Advisory Committee. Marcé International Society position statement on psychosocial assessment and depression screening in perinatal women. Best Pract Res Cl Ob. 2014; 28(1):179-87. 